\title{
SISTEM PREDIKSI PENJUALAN DENGAN METODE SINGLE EXPONENTIAL SMOOTING (STUDI KASUS CV. BU IPUNG LAMONGAN)
}

\author{
Muhammad Mathori Abdul Jali1 ${ }^{1)}$, Umi Chotijah²), Putri Aiyiyah Rakhma Devi ${ }^{3)}$ \\ ${ }^{1)} \mathrm{CV}$. Bu Ipung Lamongan \\ Jl. Dokter Wahidin Sudiro Husodo No.153, Kendaruan, Banjarmendalan, Kec. Lamongan, Kabupaten Lamongan, Jawa \\ Tmur 62212 \\ 2,3) Universitas Muhammadiyah Gresik \\ Jl. Sumatra 101 Gresik Kota Baru (GKB), Randuagung, 61121 \\ E-mail: mathorimuhammad449@gmail.com ${ }^{1)}$, umi.chotijah@gmail.com²), deviaisyiyah@umg.ac.id ${ }^{3)}$
}

\begin{abstract}
ABSTRAK
Restoran adalah istilah umum untuk menyebut usaha gestronomi yang menyajikan hidangan kepada masyarakat. Restoran biasanya memiliki spesialisasi dalam jenis makanan yang dihidangkan sebagai contoh yaitu CV. Bu Ipung Lamongan yang menyediakan berbagai macam makanan dan minuman seperti makanan tradisional, fried chicken, snack dan juga jus. Hasil dari observasi dari CV. Bu Ipung Lamongan didapatkan hasil penjualan produk dalam satu minggu, selain hasil penjualan produk ada permasalahan yang diperoleh yaitu jumlah persediaan produk yang ada di CV. Bu Ipung Lamongan tersebut masih belum beratur. Dikarenakan seringnya terjadi kekurangan serta kelebihan bahan baku yang menyebabkan kerugian bagi restoran. Meka dibutukanlah sebuah sistem prediksi yang mampu membantu CV. Bu Ipung Lamongan dalam menentukan jumlah stok bakan baku dalam satu minggu. Sistem prediksi yang dikembangkan dalam penelitian ini menggunakan metode Single Exponential Smooting dengan beberapa penujian yaitu pertama dengan data acuan 3 minggu, pengujian kedua dengan data acuan 6 minggu dan pengujian ketida dengan data acuan 12 minggu. Dari masing-masing pengujian itu akan dijadikan nilai perbandingan dengan data atual yang dapat menentukan nilai error dalam prediksi menggunakan MSE (Mean Squared Error), MAE (Mean Absolute Error), MAPE(Mean Absolute Percantage Error). Dari ketiga penujian tersebut yang memiliki nilai error terkecil merupakan hasil peramlan yang terbaik.
\end{abstract}

Kata Kunci: Single Exponential Smooting, Sitem Prediksi penjualan, MSE, MAE, MAPE

\section{ABSTRACT}

Restaurant is a general term to describe a gastronomic business that serves dishes to the public. Restaurants usually specialize in the type of food served, for example, CV. Mrs. Ipung Lamongan who provides various kinds of food and drinks such as traditional food, fried chicken, snacks and juices. The results of observations from CV. Mrs. Ipung Lamongan obtained product sales results in one week, in addition to product sales results there were problems obtained, namely the number of product inventories in CV. Mrs. Ipung Lamongan is still not in order. Due to frequent shortages and excess raw materials that cause losses for restaurants. They need a prediction system that can help CV. Mrs. Ipung Lamongan in determining the amount of raw material stock in one week. The prediction system developed in this study uses the Single Exponential Smoothing method with several tests, namely the first with 3 weeks of reference data, the second test with 6 weeks of reference data and the third test with 12 weeks of reference data. From each test it will be used as a comparison value with actual data that can determine the error value in predictions using MSE (Mean Squared Error), MAE (Mean Absolute Error), MAPE (Mean Absolute Percantage Error). Of the three tests that have the smallest error value is the best forecasting result.

Keywords: Single Exponential Smoothing, Sales Prediction System, MSE, MAE, MAPE

\section{Pendahuluan}

Restoran adalah istilah umum untuk menyebut usaha gestronomi yang menyajikan hidangan kepada masyarakat dan menyajikan tempat untuk menikmati hidangan tersebut. Meski pada umumnya restoran menyajikan makanan di tempat teteapi ada juga restoran yang menyedikan layanan online dan delivery service yang merupakan sebagai salah satu bentuk pelayanan kepada konsumennya. Restoran biasanya memiliki spesialisasi dalam jenis makanan yang dihidangkan sebagai contoh yaitu CV. Bu Ipung Lamongan yang menyediakan berbagai macam makanan dan minuman seperti makanan tradisional, fried chicken, snack dan juga jus (Studio, 2020). Dari hasil observasi di CV. Bu Ipung Lamongan yang berada di kota lamongan diperoleh informasi mengenai jumlah penjualan produk tiap minggunya. Selain jumlah paenjualan produk ada permasalahan yang diperoleh.
Permasalahan yang diperoleh adalah jumlah persediaan bahan makanan yang ada di CV. Bu Ipung Lamongan tersebut masih belum teratur. Dalam hal ini penentuan penjualan makanan pada satu minggu yang akan datang tidak dapat diketahui berapa banyak jumlah bahan makanan yang harus dibutuhkan. Apabila terjadi kekurangan atau kelebihan itu bisa menyebabkan kerugian bagi restoran serta dapat menghambat proses penjualan akibat kekurangan stok bahan makanan. Sedangkan kalau kelebihan stok bahan makanan itu juga berakibat buruk bisa menyebabkan makanan bisa basi ataupun jamuran. Oleh karena itu untuk mengatasi permasalahan yang ada di $\mathrm{CV}$. Bu Ipung Lamongan tersebut dibutuhkan sistem prediksi penjulan agar tidak terjadi kerugian lagi pada satu minggu berikutnya.

Diperlukan sebuah sistem yang dapat membantu untuk menentukan jumlah penjulan pada satu minggu berikutya dengan data penjualan pada satu minggu sebelumnya.

Sistem prediksi yang akan dikembangakan dalam 
INDEXIA: Informatic and Computational Intelegent Journal

Muhammad Mathori Abdul Jalil, Umi Chotijah, Putri Aisyiyah Rakhma Devi

Sistem Prediksi Penjualan Dengan Metode Single Exponential Smooting

penelitian ini adalah menggunakan sebuah metode Single Exponential Smoothing. Metode Single Exponential Smoothing merupakan peramalan yang digunakan untuk jaka pendek atau biasanya untuk satu minggu kedepan atau satu bulan kedepan. Model ini mengasumsikan bahwa data yang berfluktuasi berada pada nilai mean yang tetap, tanpa adanya trend ataupun pola perumbuhan yang konsisten. Metode ini dipilih karena sangat sesuai dengan kebutuhan permasalahan yang ada di $\mathrm{CV}$. Bu Ipung Lamongan, dimana peramalan yang dibutuhkan adalah untuk meramalkan jangka pendek dan data yang didapatkan pada CV. Bu Ipung lamongan merupakan data yang berpola fluktuasi secara tidak teratur. Pada analisis artikel penelitian Niken Chaerunnisa dan Ade Momon (2021) tentang perbandingan metode Single Exponential Smoothing dan Moving Average untuk meramalkan penjulan produk minyak goring di PT Tunas Baru Lampung menyatakan bahwa metode Single Exponential Smooting metode terbaik untuk meramalkan penjualan produk minyak goreng dan tingkat persentase kesalahan menggunakan metode Single Exponential Smooting lebih kecil dibandingkan metode Moving Average. Penggunaan data penjualan dan data stok persediaan bahan baku pada periode sebelumya akan digunakan sebagai acuan dalam melakuan peramalan. Dan hasil pengelolahan data tersebut akan menyimpulkan banyaknya stok bahan baku yang harus disiapkan agar persediaan stok bahan baku sesuai dengan yang diharapkan dibandingkan satu minggu sebelumnya.

Sistem prediksi penjualan ini dapat diharapkan mempermudah membantu pemilik $\mathrm{CV}$. Bu Ipung Lamongan untuk menentukan jumlah persediaan makanan untuk satu minggu kedepannya agar dapat meminimalisir kerugian yang terjadi karena kekurangan atau kelebihan bahan makanan pada minggu lalu.

\section{LANDASAN TEORI}

\subsection{Peramalan (Forecasting)}

Peramalan (forecasting) diperlukan untuk menetapkan patokan dalam membuat rencana. Tanpa adanya patokan (dasar), tidak mungkin rencana bisa dibuat. Ramalan penjualan diperlukan untuk menentukan jumlah produksi baik jasa maupun barang yang harus dipersiapkan.

\subsection{Metode Single Exponential Smoothing}

Metode Single Exponential Smoothing adalah teknik peramalan rata-rata bergerak dengan pembobotan dimana data diberi bobot oleh sebuah fungsi exponential. Penghalusan exponential merupakan metode peramalan rata-rata bergerak dengan pembobotan canggih, namun masih mudah digunakan. Metode ini sangat dedikit pencatatan data masa lalu. Rumus penghalusan exponential dapat ditunjukkan sebagai berikut:

Keterangan :

$$
\mathrm{F}_{\mathrm{t}+1}=\alpha \mathrm{X}_{\mathrm{t}}+(1-\alpha) \mathrm{F}_{\mathrm{t}-1 \ldots \ldots \ldots \ldots \ldots . . .}(2.1)
$$

$\mathrm{Ft}+1=$ Ramalan untuk periode $\mathrm{ke} \mathrm{t}+1$

$\mathrm{Xt}=$ Nilai riil periode ke $\mathrm{t}$

$\alpha=$ Bobot yang menunjukkan konstanta penghalus $(0<\alpha<1)$

Ft-1 = Ramalan untuk periode ke $\mathrm{t}-1$

Metode ini membutuhkan nilai alpha $(\alpha)$ sebagai nilai parameter pemulusan. Untuk mendapatkan nilai $\alpha$ yang tepat pada umumnya dilakukan dengan cara trial dan error untuk menentukan nilai kesalahan terendah. Nilai $\alpha$ dilakukan dengan membandingkan pemulusan antara $\alpha$ 0,1 sampai $\alpha 0,9$. Metode ini hanya mempu memprediksi peramalan maksimal satu periode kedepan dan cocok untuk data yang mengandung unsur stationer.

Ada beberapa perhitungan yang bisa digunakan untuk menghitung kesalahan peramalan total. Perhitungan ini dapat digunakan untuk membandingkan model peramalan yang berbeda, mengawasi peramalan, dan untuk memastikan peramalan berjalan dengan baik. Tiga dari perhitungan yang paling terkenal adalah error mutlak ratarata (Mean Absolute Error) MAE, kesalahan kuadrat ratarata (Mean Squared Error) MSE, dan kesalahan persen mutlak rata-rata (Mean Absolute Percent Error) MAPE.

MSE (Mean Squared Error) adalah metode lain untuk mengevaluasi metode peramalan. Masing-masing kesalahan atau sisa dikuadratkan. Kemudian dijumlahkan dan dibagi dengan jumlah observasi. Pendekatan ini mengatur kesalahan peramalan yang besar karena kesalahan-kesalahan itu dikuadratkan. Berikut rumus untuk menghitung MSE:

$$
\operatorname{MSE}=\frac{1}{n} \sum_{t}^{n}=1\left(\mathrm{X}_{\mathrm{t}}-\mathrm{F}_{\mathrm{t}}\right) 2 \ldots \ldots \ldots
$$

Keterangan :

$\mathrm{Ft}=$ Nilai ramalan

$\mathrm{Xt}=$ Niai actual

$\mathrm{n}=$ Jumlah data error

Untuk mengetahui metode prediksi dengan tingkat akurasi yang tinggi, maka dibutuhkan menghitung tingkat kesalahan dalam suatu prediksi, semakin kecil tingkat kesalahan yang dihasilkan, maka semakin baik prediksi tersebut. Standar umum pengukuran kesalahan prediksi yang digunakan adalah (Mean Absolute Error) MAE untuk akurasi, dan (Mean Absolute Percentage Error) MAPE untuk persentase akurasi. Berikut rumus untuk menghitung MAE:

$$
\mathrm{MAE}=\frac{1}{n} \sum_{t}^{n}=1\left|X_{t}-F_{t}\right| \ldots \ldots \ldots \ldots
$$

Keterangan :

$\mathrm{Ft}=$ Nilai ramalan

$\mathrm{Xt}=$ Nilai actual

$\mathrm{n}=$ Jumlah data error

MAPE (Mean Absolute Percantage Error) Metode peramalan yang baik adalah metode yang memberikan tingkat kesalahan yang kecil, tingkat kesalahan merupakan selisih antara nilai aktual dengan nilai peramalan. Kesalahan dalam peramalan dapat disebabkan karena nilai peramalan terlalu kecil atau terlalu besar dibandingkan nilai aktual. Teknik perhitungan MAPE dapat dihitung dengan rumus sebagai berikut.

MAPE $=\frac{1}{n} \sum_{t=1}^{n} \frac{\left|\mathrm{X}_{\mathrm{t}}-\mathrm{F}_{\mathrm{t}}\right|}{\mathrm{X}_{\mathrm{t}}} \mathrm{X} 100 \ldots \ldots \ldots$

Keterangan

$\mathrm{Ft}=$ Nilai ramalan

$\mathrm{Xt}=$ Nilai actual

$\mathrm{n}=$ Jumlah data error

\section{ANALISIS DAN PERANCANGAN SISTEM}

\subsection{Analisis Sistem}

Wawancara dengan pihak manajemen $\mathrm{CV}$. Bu Ipung Lamongan menyatakan bahwa, setiap bulan pihak 
INDEXIA: Informatic and Computational Intelegent Journal

Muhammad Mathori Abdul Jalil, Umi Chotijah, Putri Aisyiyah Rakhma Devi

Sistem Prediksi Penjualan Dengan Metode Single Exponential Smooting

peusahaan kususnya devisi penjualan dan pihak manajemen akan melakuan rapat untuk melakukan evaluasi penjualan, menentukan target penjualan dan sterategi yang di gunakan untuk bulan depan. Dalam rapat tersebuat akan menghasilkan keputusan berupa perancangan kerja yang digunakan untuk target penjualan untuk bulan depan. Berdasarkan penjelasan tersebut dalam melakukan penggadaan jumlah makanan yang akan dijual maka terlebih dahulu perusahaan harus menentukan target penjualan. Target penjualan ini sangat penting karena dapat memberikan gambaran tentang masa depan perusahaan yang memungkinkan manajemen membuat perancangan, menciptakan peluang bisnis, maupun mengatur pola investasi mereka.

Penjualan makanan masih sering terjadi fluktuasi penjualan, sehingga apabila pengadaan terlalu besar maka perusahaan akan mengalami kerugian, sebaliknya juga bila pengadaan diadakan terlalu sedikit maka perusahaan mendapat keluhan dari pelanggan karena membuat pelanggan menunggu dalam waktu yang lama. Dengan kata lain, keberhasilan suatu perusahaan sangat tergantung pada kemampuan manajemen dalam memanfaatkan peluang agar dapat menghasilkan penjualan dan laba sesuai dengan yang diharapkan.

Sistem yang membantu dalam prediksi penjualan akan sangat membantu dalam proses penjulan di CV. Bu Ipung Lamongan. Karena dengan adanya sistem tersebut dapat membantu dalam mengambil keputusan penjualan pada minggu selanjutnya.

\subsection{Hasil Analisis}

Sistem yang akan dibangun termasuk ke dalam sistem peramalan (forecasting). Sistem ini harus mampu memprediksi penjualan makanan untuk satu minggu selanjutnya berdasarkan data dari minggu-minggu sebelumnya.

Sistem peramalan ini juga digunakan oleh pikak manajemen dan devisi penjualan untuk menentukan prediksi yang diberikan oleh sistem. Berdasarkan hal terebut terdiri dari 2 entitas, yaitu:

1. Manajer : merupakan entitas yang bertanggung jawab penuh terhadap berjalannya usaha dan bertanggung jawab atas pengambilan keputusan peramalan yang dilakukan oleh sistem.

2. Karyawan : merupakan entitas yang bertugas untuk memasukkan data perminggu serta mengatur persediaan stok produk.

Berikut adalah diagram alir sisem prediksi penjualan produk di CV. Bu Ipung Lamongan yang dapat dilihat pada gambar 3.1 dibawah ini:

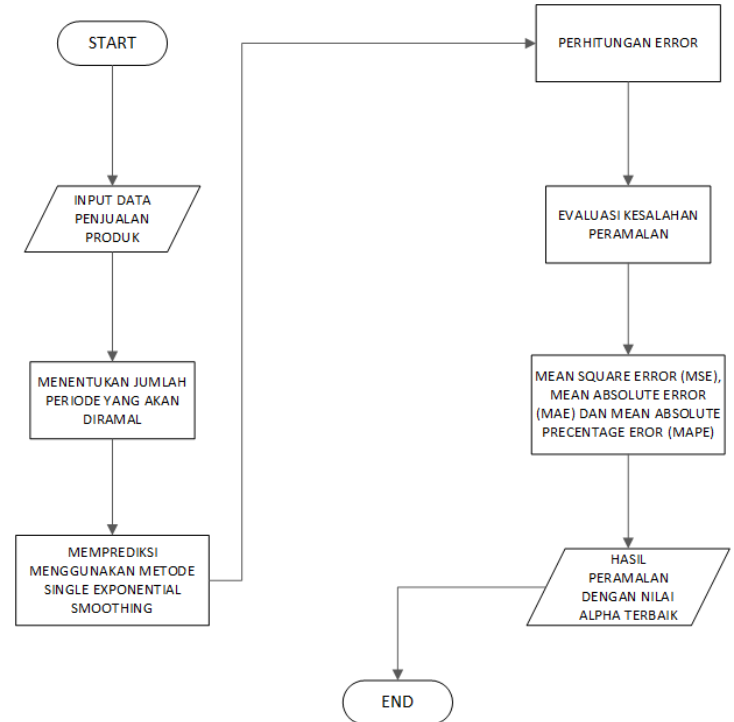

Gambar 3.1 Diagram Alir Sistem Prediksi Penjualan Produk CV. Bu Ipung Lamongan

Berdasarkan gambar 3.1 proses prediksi penjualan produk dimulai dengan memasukkan data penjualan produk pada minggu sebelumnya. Kemudian sistem memulai meprediksi penjualan menggunakan metode Single Exponential Smoothing yang kemudian setelah proses peramalan selesai sistem akan menampilkan hasil peramalan dengan nilai alpha terbaik. Berikut merupakan 3.2 diagram alir metode Single Exponential Smoothing:

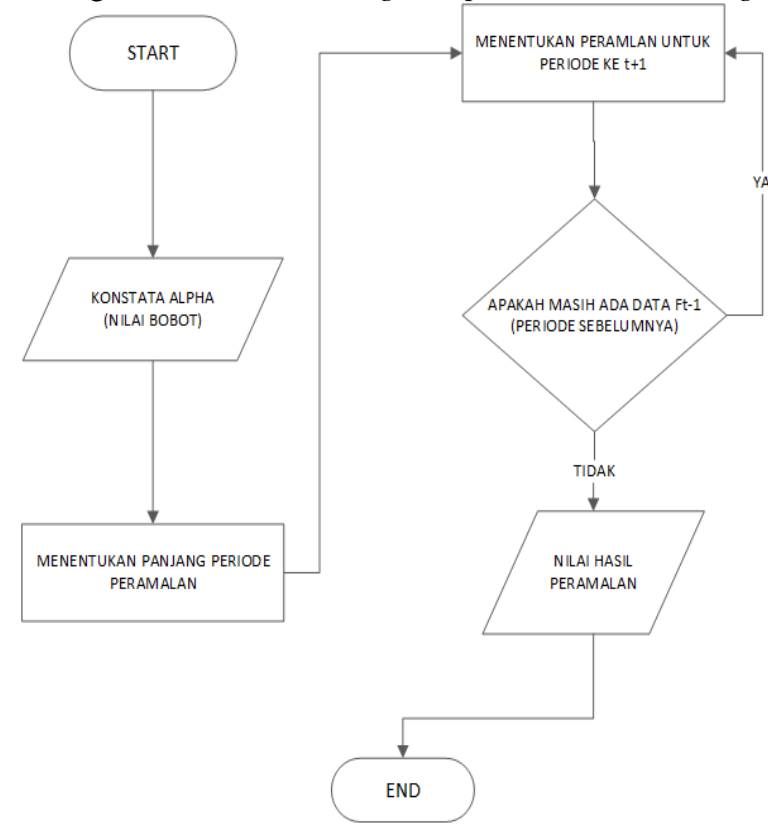

Gambar 3.2 Diagram Alir Metode Single Exponential Smoothing

Keterangan diagram alir metode Single Exponential Smoothing

1. Nilai bobot alpha akan secara otomatis diisi oleh sistem yang selanjutnya nilai terebut akan digunakan untuk menentukan pemulusan peramlan.

2. Menentukan jumlah periode peramalan yang nantinya akan digunakan untuk proses dasar menentukan peramalan .

3. Kemudian perhitungan dilanjutkan dengan menentukan nilai peramalan menggunakan persamaan

4. Perulangan akan dilakukan jika ada data periode sebelumya maka perhitungan akan dilanjutkan dan 
INDEXIA: Informatic and Computational Intelegent Journal

Muhammad Mathori Abdul Jalil, Umi Chotijah, Putri Aisyiyah Rakhma Devi

Sistem Prediksi Penjualan Dengan Metode Single Exponential Smooting

jika proses perhitungan selesai maka akan menampilkan hasil peramalan untuk satu minggu berikutnya.

\subsection{Diagram Konteks}

Diagram kontext adalah diagram yang terdiri dari suatu proses dan menggambarkan ruang lingkup suatu sistem. Diagram kontext merupakan level tertinggi dari DFD yang menggambarkan seluruh input ke sistem output dari sistem. Adapun diagram kontext dari sistem yang akan dibuat adalah seperti gambar 3.3 sebagai berikut.

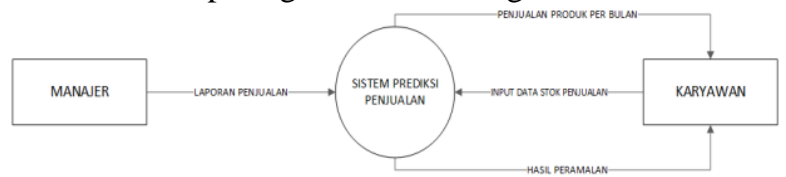

Gambar 3.3 Diagram Kontext Sistem Prediksi Penjualan Produk

Diagram kontext diatas merupakan gambaran sistem secara garis besar dimana terdapat dua entitas yang berhubungan dengan sistem.

1. Manager merupakan pihak yang dapat meihat laporan penjualan pada tiap perbulannya.

2. Karyawan merupakan pihak yang bertugas untuk mengelola stok pejualan perminggu, memesukkan data penjualan perbulan serta memperoleh hasil peramalan

\subsection{Diagram Berjenjang}

Dalam pembuatan sistem diperlukanlah sebuah bagan berjenjang yang dimana merupakan awal dari penggambaran DFD (Data Flow Diagram) ke level -level yang lebih bawah lagi. Dari sistem perediksi ini mempunyai 3 level seperti terlihat pada gambar 3.4 dibawah ini.

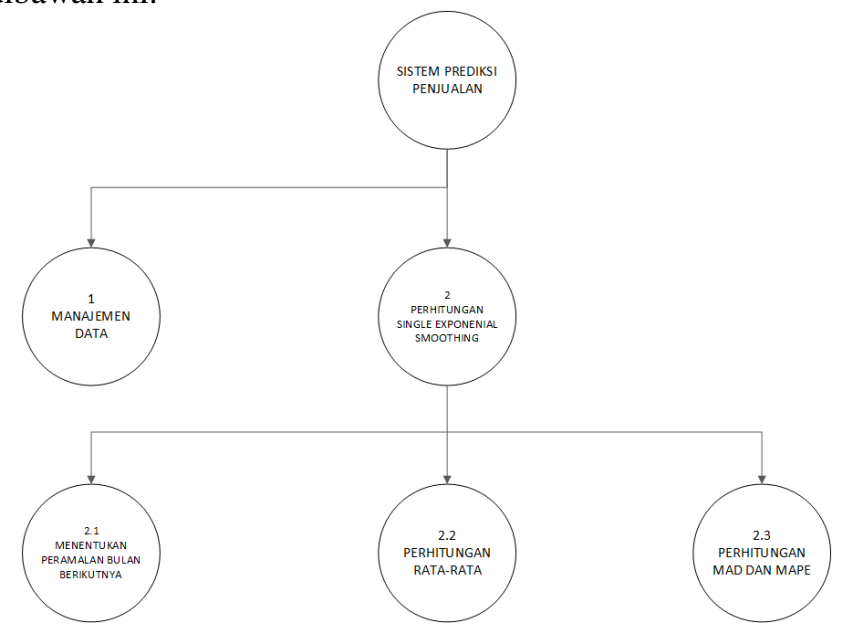

Gambar 3.4 Diagram Berjenjang Sistem Perediksi Penjualan Peroduk

Pada gambar 3.5 dapat dijelaskan sebagai beikut:

5. Top Level :

Sistem Perdiksi Penjualan

6. Level 0 :

1. Manajemen data

2.Perhitungan Single Exponential Smoothing

7. Level 1

1. Menentukan peramalan satuminggu berikutnya

2. Menghitung rata-rata.

3. Perhitungan MAE dan MAPE.

3.5 Data Flow Diagram Level 0

\section{IMPLEMENTASI DAN PENGUJIAN SISTEM}

\subsection{Implementasi Halaman Login}


INDEXIA: Informatic and Computational Intelegent Journal

Muhammad Mathori Abdul Jalil, Umi Chotijah, Putri Aisyiyah Rakhma Devi

Sistem Prediksi Penjualan Dengan Metode Single Exponential Smooting

Berikut ini adalah tampilan awal sistem saat user membuka sistem. Tampilan login ini digunakan untuk membatasi pemekaian sistem prediksi agar tidak digunakan oleh orang lain. Berikut ini adalah gambar tampilan halaman login yang telah dirancang seperti gambar 4.1 dibawah ini:

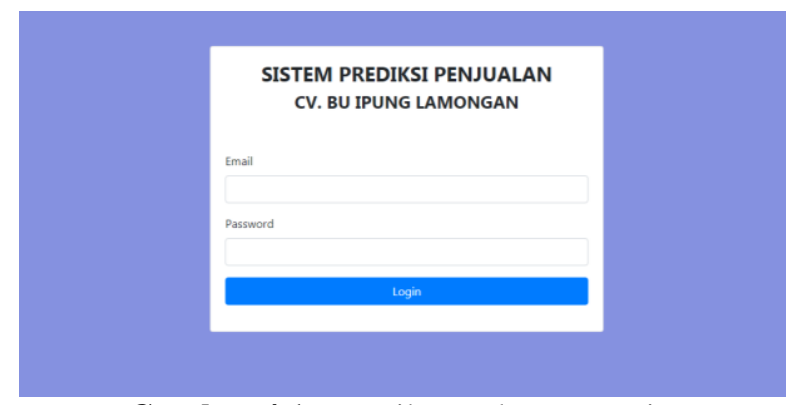

Gambar 4.1 Tampilan Halaman Login

\subsection{Implementasi Halaman Dashboard}

Setelah user berhasil melakukan login maka user akan diarahkan oleh sistem ke halaman Dashboard. Berikut ini adalah tampilan halaman Dashboard seperti gambar 4.2 dibawah ini:
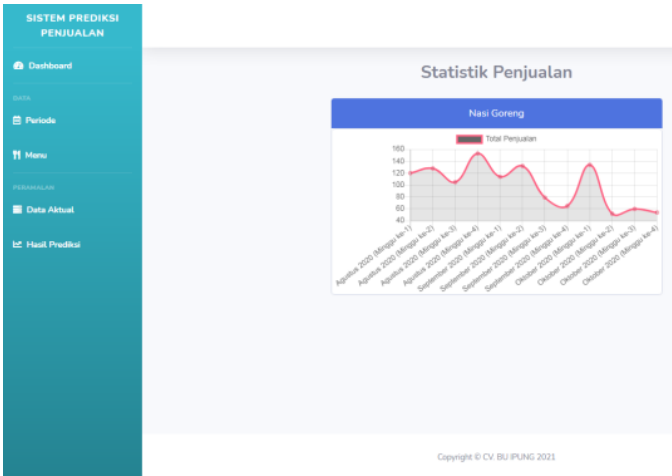

Gambar 4.2 Tampilan Halaman Dashboard

\subsection{Implementasi Halaman Periode}

Halaman seperti gambar 4.3 dibawah ini adalah halaman untuk menambahkan data periode dalam 1 bulan pada sistem prediksi penjualan:
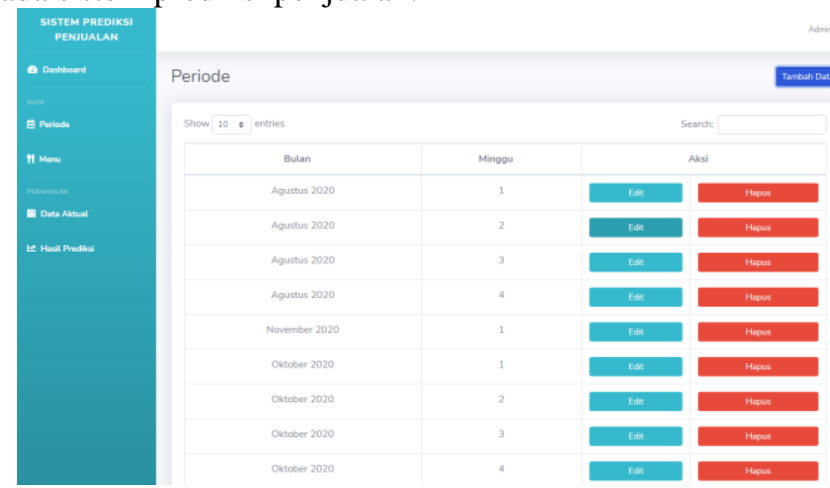

Gambar 4.3 Tampilan Halaman Periode

\subsection{Implentasi Halaman Menu}

Dibawah ini adalah tampilan halaman menu yang dapat dilihat pada gambar 4.4 yang digunakan untuk menambahkan data menu-menu yang ada di $\mathrm{CV}$. Bu Ipung Lamongan.

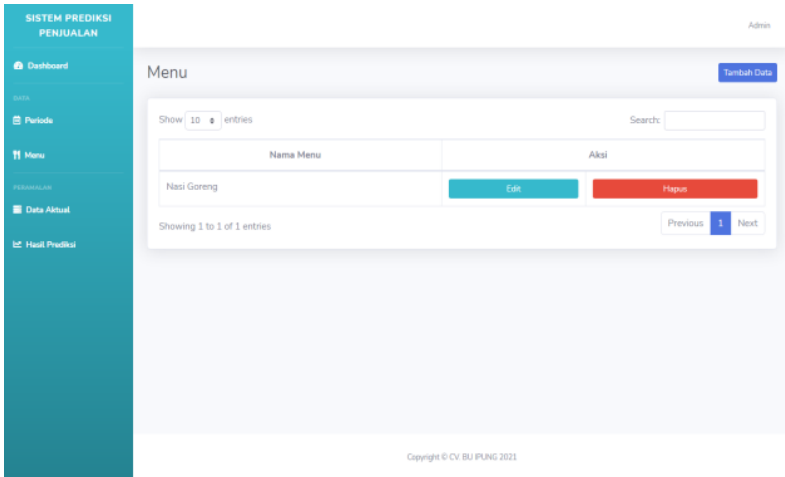

Gambar 4.4 Tampilan Halaman Menu

\subsection{Implementasi Halaman Data Aktual}

Pada halaman ini berfungsi untuk menambahkan data aktual produk di CV. Bu Ipung Lamongan serta juga dapat digunakan untuk menghapus dan mengedit data aktual produk.

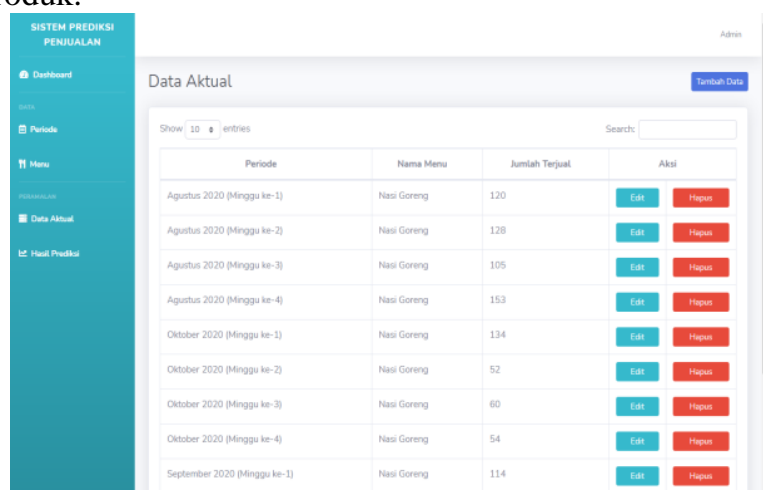

Gambar 4.3 Tampilan Halaman Data Aktual

\subsection{Implementasi Halaman Peramalan}

Pada halaman ini digunakan untuk melakukan peramalan stok bahan produk pada minggu berikutnya. Dibawah ini merupakan gambar 4.6 tampilan halaman peramalan.

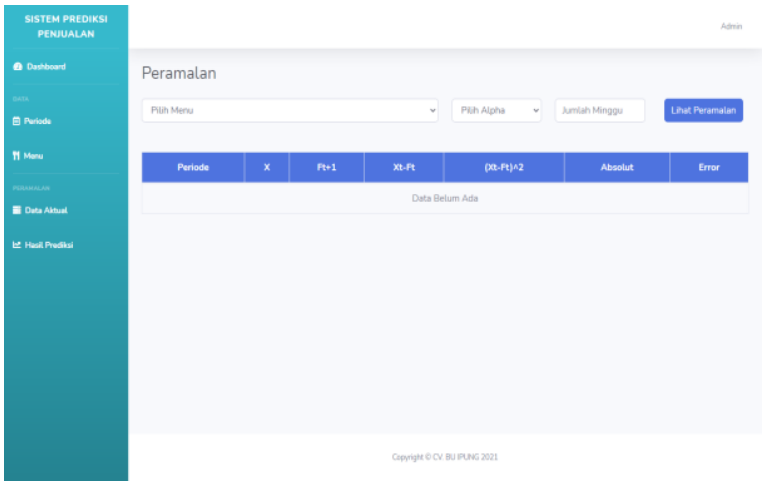

Gambar 4.6 Tampilan Halaman Peramalan

\subsection{Pengujian Sistem}

Untuk analisa hasil pengujian sistem penulis menggunakan data aktual produk penjualan pada $\mathrm{CV} . \mathrm{Bu}$ Ipung Lamongan selama 27 minggu. Didalam pengujian sistem menggunakan 3 acuan peramalan yaitu dengan data acuan 3 minggu, 6 mimggu, 12 minggu. Dari data acuan yang digunakan mulai dari bulan Agustus 2020 minggu ke 1 - Oktober 2020 minggu ke 4. Pada pengujian ini dilakukan 3 tahap pengujian dengan kiteria sebagai berikut:

1. Kiteria pertama peramalan produk nasi goreng menggunakan data acuan 3 minggu mulai bulan Agustus 2020 minggu ke 1 - Oktober 2020 minggu 
INDEXIA: Informatic and Computational Intelegent Journal

Muhammad Mathori Abdul Jalil, Umi Chotijah, Putri Aisyiyah Rakhma Devi

Sistem Prediksi Penjualan Dengan Metode Single Exponential Smooting

ke 4. Untuk menentukan peramalan bulan Agustus 2020 minggu ke 4 dengan besaran nilai alpha mulai 0,1 - 0,9 untuk mengetahui hasil peramalan yang terbaik maka di cari nilai error MAPE terkecil.

2. Kiteria pertama peramalan produk nasi goreng menggunakan data acuan 6 minggu mulai bulan Agustus 2020 minggu ke 1 - Oktober 2020 minggu ke 4. Untuk menentukan peramalan bulan Oktober 2020 minggu ke 3 dengan besaran nilai alpha mulai 0,1 - 0,9 untuk mengetahui hasil peramalan yang terbaik maka di cari nilai error MAPE terkecil.

3. Kiteria pertama peramalan produk nasi goreng menggunakan data acuan 12 minggu mulai bulan Agustus 2020 minggu ke 1 - Oktober 2020 minggu ke 4. Untuk menentukan peramalan bulan November minggu ke 1 dengan besaran nilai alpha mulai 0,1 - 0,9 untuk mengetahui hasil peramalan yang terbaik maka di cari nilai error MAPE terkecil.

\subsubsection{Kiteria Pengujian Pertama Dengan Data Acuan 3 Minggu}

Tabel 4.1 Hasil Peramalan Dengan Data Acuan 3 Minggu Alpha 0,1-0,9

\begin{tabular}{|c|c|c|c|c|c|}
\hline No & $\begin{array}{c}\text { Nama } \\
\text { Produk }\end{array}$ & Periode & Alpha & MAPE & $\begin{array}{c}\text { Hasil Pera- } \\
\text { malan }\end{array}$ \\
\hline 1 & \multirow{9}{*}{$\begin{array}{l}\text { Nasi } \\
\text { Goreng }\end{array}$} & $\begin{array}{c}\text { Agus } 2020 \\
\text { minggu } 4\end{array}$ & 0,1 & $7 \%$ & 126 \\
\hline 2 & & $\begin{array}{c}\text { Agus } 2020 \\
\text { minggu } 4\end{array}$ & 0,2 & $6 \%$ & 123 \\
\hline 3 & & $\begin{array}{c}\text { Agus } 2020 \\
\text { minggu } 4\end{array}$ & 0,3 & $5 \%$ & 121 \\
\hline 4 & & $\begin{array}{c}\text { Agus } 2020 \\
\text { minggu } 4\end{array}$ & 0,4 & $4 \%$ & 119 \\
\hline 5 & & $\begin{array}{c}\text { Agus } 2020 \\
\text { minggu } 4\end{array}$ & 0,5 & $4 \%$ & 117 \\
\hline 6 & & $\begin{array}{c}\text { Agus } 2020 \\
\text { minggu } 4\end{array}$ & 0,6 & $3 \%$ & 114 \\
\hline 7 & & $\begin{array}{c}\text { Agus } 2020 \\
\text { minggu } 4\end{array}$ & 0,7 & $2 \%$ & 112 \\
\hline 8 & & $\begin{array}{c}\text { Agus } 2020 \\
\text { minggu } 4\end{array}$ & 0,8 & $3 \%$ & 108 \\
\hline 9 & & $\begin{array}{c}\text { Agus } 2020 \\
\text { minggu } 4\end{array}$ & 0,9 & $1 \%$ & 107 \\
\hline
\end{tabular}

Dari tabel diatas didapatkan hasil peramalan yang mendekati dan memperoleh nilai kesalahan peramalan MAPE terkecil dibesaran nilai alpha 0,9 seperti di Tabel 4.1 yang berwarna kuning. Dari tabel diatas dapat dilihat nilai hasil pengujian peramalan dan kesalahan peramalan alpha terpilih dengan MAPE terkecil sebagai berikut:

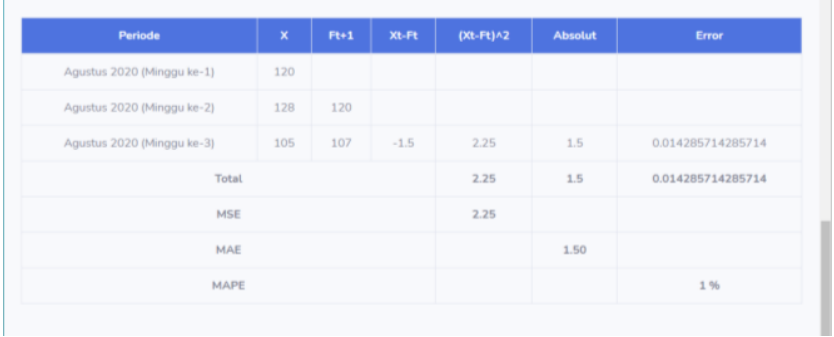

Jadi peramalan penjualan produk nasi goreng menggunakan acuan 6 minggu untuk periode Oktober 2020 minggu ke 3 adalah 60 dengan nilai MSE 16.63, MAE 2.87 dan MAPE $4 \%$.

\subsubsection{Kiteria Pengujian Kedua Dengan Data Acuan 6 Minggu}

Tabel 4.2 Hasil Peramalan Dengan Data Acuan 6 Minggu Alpha 0,1-0,9

\begin{tabular}{|c|c|c|c|c|c|}
\hline No & $\begin{array}{c}\text { Nama } \\
\text { Produk }\end{array}$ & Periode & Alpha & MAPE & $\begin{array}{c}\text { Hasil Per- } \\
\text { amalan }\end{array}$ \\
\hline 1 & \multirow{9}{*}{ Nasi Goreng } & Okt 2020 minggu ke 3 & 0,1 & $34 \%$ & 126 \\
\hline 2 & & Okt 2020 minggu ke 3 & 0,2 & $30 \%$ & 118 \\
\hline 3 & & Okt 2020 minggu ke 3 & 0,3 & $26 \%$ & 109 \\
\hline 4 & & Okt 2020 minggu ke 3 & 0,4 & $23 \%$ & 101 \\
\hline 5 & & Okt 2020 minggu ke 3 & 0,5 & $19 \%$ & 93 \\
\hline 6 & & Okt 2020 minggu ke 3 & 0,6 & $15 \%$ & 85 \\
\hline 7 & & Okt 2020 minggu ke 3 & 0,7 & $11 \%$ & 77 \\
\hline 8 & & Okt 2020 minggu ke 3 & 0,8 & $8 \%$ & 68 \\
\hline 9 & & Okt 2020 minggu ke 3 & 0,9 & $4 \%$ & 60 \\
\hline
\end{tabular}

Dari tabel diatas didapatkan hasil peramalan yang mendekati dan memperoleh nilai kesalahan peramalan MAPE terkecil dibesaran nilai alpha 0,9 seperti di Tabel 4.2 yang berwarna kuning. Dari tabel diatas dapat dilihat nilai hasil pengujian peramalan dan kesalahan peramalan alpha terpilih dengan MAPE terkecil sebagai berikut:

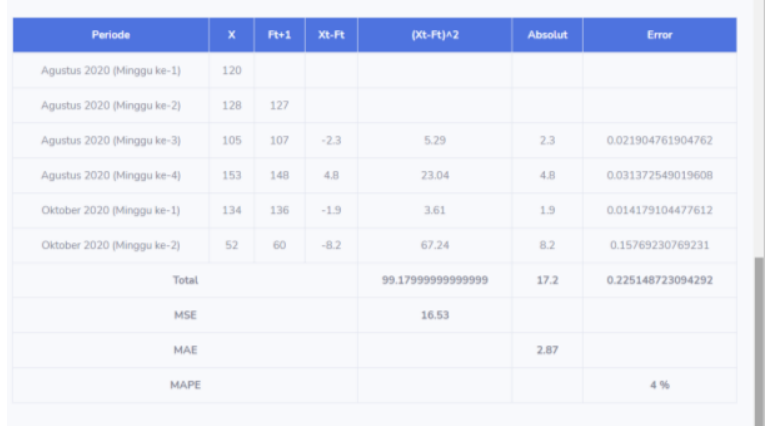

Jadi peramalan penjualan produk nasi goreng menggunakan acuan 6 minggu untuk periode Oktober 2020 minggu ke 3 adalah 60 dengan nilai MSE 16.63, MAE 2.87 dan MAPE $4 \%$.

\subsubsection{Kiteria Pengujian Ketiga Dengan Data Acuan 12 Minggu}

Tabel 4.3 Hasil Peramalan Dengan Data Acuan 12 Minggu Alpha 0,1-0,9

\begin{tabular}{|c|c|c|c|c|c|}
\hline No & $\begin{array}{c}\text { Nama } \\
\text { Produk }\end{array}$ & Periode & Alpha & MAPE & $\begin{array}{c}\text { Hasil } \\
\text { Peramalan }\end{array}$ \\
\hline 1 & \multirow{9}{*}{$\begin{array}{l}\text { Nasi } \\
\text { Goreng }\end{array}$} & Nov 2020 minggu ke & 0,1 & $38 \%$ & 98 \\
\hline 2 & & Nov 2020 minggu ke & 0,2 & $31 \%$ & 83 \\
\hline 3 & & Nov 2020 minggu ke & 0,3 & $25 \%$ & 73 \\
\hline 4 & & $\begin{array}{c}\text { Nov } 2020 \text { minggu ke } \\
1\end{array}$ & 0,4 & $21 \%$ & 68 \\
\hline 5 & & $\begin{array}{c}\text { Nov } 2020 \text { minggu ke } \\
1\end{array}$ & 0,5 & $17 \%$ & 62 \\
\hline 6 & & $\begin{array}{c}\text { Nov } 2020 \text { minggu ke } \\
1 \\
\end{array}$ & 0,6 & $13 \%$ & 59 \\
\hline 7 & & Nov 2020 minggu ke & 0,7 & $10 \%$ & 57 \\
\hline 8 & & $\begin{array}{c}\text { Nov } 2020 \text { minggu ke } \\
1\end{array}$ & 0,8 & $7 \%$ & 55 \\
\hline 9 & & Nov 2020 minggu ke & 0,9 & $3 \%$ & 55 \\
\hline
\end{tabular}

Dari tabel diatas didapatkan hasil peramalan yang mendekati dan memperoleh nilai kesalahan peramalan MAPE terkecil dibesaran nilai alpha 0,9 seperti di Tabel 
INDEXIA: Informatic and Computational Intelegent Journal

Muhammad Mathori Abdul Jalil, Umi Chotijah, Putri Aisyiyah Rakhma Devi

Sistem Prediksi Penjualan Dengan Metode Single Exponential Smooting

4.3 yang berwarna kuning. Dari tabel diatas dapat dilihat nilai hasil pengujian peramalan dan kesalahan peramalan alpha terpilih dengan MAPE terkecil sebagai berikut:

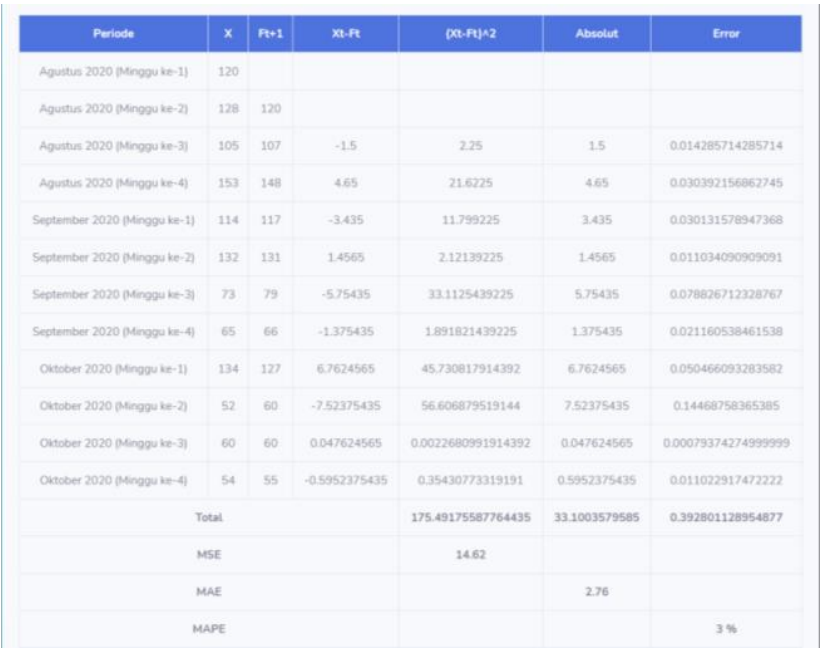

Jadi peramalan penjualan produk nasi goreng menggunakan acuan 12 minggu untuk periode November 2020 minggu ke 1 adalah 55 dengan nilai MSE 14,62, MAE 2.76 dan MAPE 3\%.

\section{KESIMPULAN DAN SARAN}

\subsection{Kesimpulan}

Berdasarkan hasil penelitian yang telah dilakukan di $\mathrm{CV}$. Bu Ipung Lamongan, untuk mengetahui hasil jumlah persediaan stok bahan baku dalam memenuhi permintaan pelanggan di minggu berikutnya telah tercapai dengan hasil sebagai berikut:

1. Metode Single Exponential Smoothing dapat digunakan untuk studi kasus peramalan persediaan bahan baku di CV. Bu Ipung Lamongan dalam periode perminggu.

2. Metode ini perlu melakukan perbandingan menggunakan nilai parameter alpha 0,1 sampai alpha 0,9 untuk menemukan nilai error yang terkecil.

3. Jika data aktualnya tidak stabil maka saat melakukan prediksi dapat menggunakan nilai alpha yang terbesar, tetapi jika sebaliknya data aktualnya stabil maka dapat menggunakan nilai alpha yang terkecil.

4. Sistem ini memerukan data acuan 27 minggu yaitu bulan agustus 2020 - maret 2021

5. Berdasarkan pengujian yang telah dilakukan pada penjualan nasi goreng, penyetan ayam, air mineral dan jus alpukat dengan menggunakan data acuan 27 minggu dari bulan agustus 2020 - maret 2021 didapatkan hasil MAPE terkecil yaitu nasi goreng $3,12 \%$, penyetan ayam $9,33 \%$, air mineral $4,14 \%$ dan jus alpukat 3,22\% menggunakan nilai alpha 0,9 .

6. Sistem ini hanya dapat meramalkan satu periode kedepan saja tidak dapat digunakan untuk melakukan peramalan beberapa periode kedepan dalam satu peralaman.

\subsection{Saran}

Saran yang dapat disampaikan untuk pengembangan sistem ini adalah sebagai berikut:
1. Diharapkan sistem peramalan ini dapat meramalkan persediaan bahan baku untuk beberapa minggu kedepan tidak hanya satu minggu kedepan saja

2. Untuk penelitian berikutnya diharapkan sistem ini bisa dikembangkan menjadi berbasis mobile androis atau IOS

3. Diharapkan untuk penelitian berikutnya menggunakan algoritma peramalan yang memiliki pola trend seperti algoritma Moving Average, ARIMA, Trend Linier Analysis. Dll.

\section{DAFTAR PUSTAKA}

[1] Basu Swastha dan Irawan. (1997). Manajemen Pemasaran Modern. Libery.

[2] Fachrurrazi, S., Si, S., \& Kom, M. (2015). MENGGUNAKAN METODE SINGLE EXPONENTIAL SMOOTHING PADA TOKO OBAT BINTANG GEURUGOK.

[3] Pamuji. (1981). Teori Sistem dan Penerapannya dalam Manajemen. http://digilib.uinsby.ac.id/8536/3/Bab2.pdf.

[4] Setiawan. (2021). Pengertian Penjualan - Jenis, Tujuan, Faktor, Pasar, Para Ahli. https://www.gurupendidikan.co.id/pengertianpenjualan

[5] Studio, A. (2020). Pengertian Restoran Menurut Para Ahli. https://www.arsitur.com/2015/10/pengertianrestoran-menurut-para-ahli.html

[6] Gustriansyah, R. (2017). ANALISIS METODE SINGLE EXPONENTIAL SMOOTHING DENGAN BROWN EXPONENTIAL SMOOTHING PADA STUDI KASUS. 7-11.

[7] Laksmana, R. D., Santoso, E., \& Rahayudi, B. (2019). Prediksi Penjualan Roti Menggunakan Metode Exponential Smoothing ( Studi Kasus: Harum Bakery ). 3(5), 4933-4941.

[8] Putro, B., Furqon, M. T., \& Wijoyo, S. H. (2018). Prediksi Jumlah Kebutuhan Pemakaian Air Menggunakan Metode Exponential Smoothing ( Studi Kasus : PDAM Kota Malang ). 2(11), 46794686.

[9] M. Syaichuddin. (2019). PERAMALAN KUANTITI PENJUALAN HERBISIDA MENGGUNAKAN METODE SINGLE EXPONENTIAL SMOOTHING STUDI KASUS PT. PETROKIMIA KAYAKU. 9.

[10] Sungkawa, I., \& Megasari, R. T. (2011). NILAI RAMALAN DATA DERET WAKTU DALAM SELEKSI MODEL PERAMALAN VOLUME PENJUALAN PT SATRIAMANDIRI CITRAMULIA Iwa Sungkawa; Ries Tri Megasari. 2(2), 636-645. 